done. I may say that I was exceedingly pleased with Cane Hill Asylum and what I was saying about the importance of the sympathetic association of the medical officers and attendants with the patients struck me as more fully illustrated there than in any place I have ever been to. I noticed this both on the female and on the male side. I think if you enlarge the place you will stifle the whole thing.'

Well, of course, the place was enlarged, but perhaps 'the whole thing' was not entirely stifled.

Another aspect of how mental health policy was swayed and eventually directed may now be considered. This was the persistent agitation, dating back probably to the publication in the 1860s of Charles Reade's Hard Cash, for more stringent safeguards against the illegal detention of 'alleged lunatics', especially for private patients. Lewis Dillwyn, MP for Swansea, carried the agitation into Parliament, and although the Select Committee of 1877 , over which he himself presided, after extensive examination of witnesses, had found no evidence of illegal practices, he continued year after year to introduce Bills purporting to establish some quasijudicial procedure in the shape of an order made by a magistrate or some other legal personage. The subsequent events have been well documented, especially in the context of Lord Shaftesbury's attitude-how he vigorcusly opposed both the Bills introduced by Dillwyn and the subsequent Government Bills on similar lines, to the extent of resigning temporarily his chairmanship of the Commissioners, so that new legislation was not enacted till after his death.

I should now like to refer to the exhaustive study of 'Evolution of the Reception Order' published in our Journal in 1927 (Vol. 73, pp 607-35) by my one-time chief and Senior Editor of our Journal, the late Dr J.R. Lord. Lord examined the question of why Lord Shaftesbury, who had helped to fashion the procedure applying to 'pauper' lunatics, the great majority, which included a magistrate's order, should have strenuously opposed the suggestion a similar procedure should also apply to private patients. And he answered as follows: the intervention of the magistrate was necessary to ensure that patients in need of asylum care and treatment were not wrongly retained in workhouses and gaols; whereas for private patients the magistrate would be an obstacle to treatment in two ways: in acute cases there would be delay in obtaining the Reception Order; in all cases it would increase the reluctance of friends and relatives to seek care and treatment at an early (which was always thought to be synonymous with a curable) stage of illness.

Lord's final conclusion was prophetic of further advances: (1) that the clearance of the workhouses, prisons, etc., of their insane inmates and the alleviation of the conditions under which the mentally afflicted poor suffered and died could not have come about without judicial intervention and the aid of the strong arm of the law. (2) These having been largely effected, there appear to be no longer any grounds for the continuation of judicial intervention in rate-aided cases of mental disorder.

Lord's expectation was, of course, realized in the 1959 Mental Health Act. Lord Shaftesbury, however, was fighting a losing battle, for the 1890 Act did provide for a magistrate's reception order for all classes of patients. This Act has been described as 'the triumph of legalism' and as having retarded the progress of psychiatry for many years. I have not been able to agree with this view, as the changes were comparatively few: the extension of the magistrate's order affected only a minority of patients, and the only other changes of importance were those requiring 're-certification at stated intervals. Even the absence of any provision for voluntary admission to public asylums cannot have been disastrous, as there is no evidence that such patients in the conditions existing at the time (an early schizophrenic, for instance) would have derived any benefit from residence in an asylum. To my mind the real obstacle to progress was the reluctance of Government, of local and Poor-Law authorities and of the voluntary hospitals to do anything for sufierers from mental illness other than by the building of asylums.

It is pleasant to be able to conclude with a brief mention of one progressive piece of legislation which belongs to our period, namely the Idiot's Act of 1886. Although the purpose of the Act was simple, its length short, and although its principles were clearly explained, and the text reproduced in full in the Journal of Mental Science for 1887, it has been strangely misunderstood by some writers of psychiatric history. One writer asserted that it authorized the building by County Councils of special asylums for the mentally defective; this was actually included in the Lunacy Act of 1890 , though very few authorities took advantage of this clause. All the 1886 Act did was to simplify and make less onerous the procedure for admitting 'imbeciles and idiots' to institutions specially designed for them (such as Earlswood, the Royal Albert, etc). For the prevention of abuse, the class of persons entitled to those new procedures had to be defined. But large numbers of defectives still had to be admitted to ordinary county asylums, and for these no special procedure seemed necessary and they were provided for in the general Lunacy Acts, though once in the asylum they were shown as a separate category in the returns sent to the Commissioners. There was thus no real contradiction between the two Acts, as has been alleged.

\title{
Election of Editor
}

As Members and Fellows will know, the result of the recent ballot was so close that under the Bye-Laws there must be a second ballot between the two candidates who gained the highest number of votes-Dr H. Freeman and Professor E. Paykel. 